Bryant University

Bryant Digital Repository

2-9-2021

\title{
Child Life Specialists' Evaluation of Hospital Playroom Design: A Mixed Method Inquiry
}

Nanci Weinberger

Bryant University, nweinber@bryant.edu

Allison Butler

Bryant University, abutler@bryant.edu

Beth Mcgee

University of Florida

Phyllis A. Schumacher

Ryan Linn Brown

Follow this and additional works at: https://digitalcommons.bryant.edu/apjou

Part of the Other Psychology Commons

\section{Recommended Citation}

Weinberger, Nanci; Butler, Allison; Mcgee, Beth; Schumacher, Phyllis A.; and Brown, Ryan Linn, "Child Life Specialists' Evaluation of Hospital Playroom Design: A Mixed Method Inquiry" (2021). Applied Psychology Journal Articles. Paper 54.

https://digitalcommons.bryant.edu/apjou/54

This Article is brought to you for free and open access by the Applied Psychology Faculty Publications and Research at Bryant Digital Repository. It has been accepted for inclusion in Applied Psychology Journal Articles by an authorized administrator of Bryant Digital Repository. For more information, please contact dcommons@bryant.edu. 


\title{
Child Life Specialists' Evaluation of Hospital Playroom Design: A Mixed Method Inquiry
}

\author{
Nanci Weinberger, Ph.D., and Allison G. Butler, Ph.D., Bryant University, and \\ Beth McGee, M.S., University of Florida, and Phyllis A. Schumacher, Ph.D., and \\ Ryan Linn Brown, B.A., Bryant University
}

\begin{abstract}
This study uses the expertise of child life specialists to identify which elements support child life goals for hospitalized children. This study can be used to inform those interested in the optimal design of hospital playrooms. Ninety child life specialists were surveyed using a photograph methodology showing five actual child life playrooms from different hospitals. The participants were asked the following: rate each playroom on 14 dimensions; describe what was liked best about each playroom; and finally, rank order the playrooms based on their ability to support child life goals. Findings show that child life specialists were able to detect fine distinctions among hospital playrooms; thus, highlighting the important role that child life specialists can play in the design or modification of these spaces. Notably, using both Likert ratings and open-response questions, the value of biophilia in child life play spaces, specifically windows, light, and nature themes were revealed. In addition to biophilic attributes, the playrooms rated most favorably were those that contain pleasing color and décor and plenty of open space. Playrooms that promote sensory-motor and pretend play were also preferred.
\end{abstract}

\section{Introduction}

Countless children face chronic illness and hospitalization each year. These difficult and often unexpected experiences can be traumatic for children of all ages and are associated with feelings of fear, confusion, loss of control, and isolation (Child Life Council [CLC], 2011; Theofanidis, 2007). The stress can be overwhelming, even interfering with development and causing lasting negative effects on children's physical and emotional health (CLC, 2011; Rennick \& Rashotte, 2009; Stowman, Kearney, \& Daphtary, 2015).

Certified child life specialists are child development experts who specialize in helping children and their families cope with the stress and uncertainty of medical treatments, illness, injury, disability, and hospitalization (CLC, 2011). Child life work has a nearly 100 -year history of supporting children and families in hospital settings. By the 1980s, the CLC was established, and a system of professional certification began (CLC, 2011). Child life specialists work as part of the healthcare team of doctors, nurses, social workers, and other professionals (American Academy of Pediatrics [AAP], 2014). They use a variety of coping techniques that may include explaining medical procedures to children using developmentally appropriate language, directly teaching strategies to reduce anxiety and foster cooperation with other members of the medical team, offering support and distraction during medical treatments and procedures, providing information and advocacy for parents and families, and offering opportunities for play "to encourage normal development and a sense of FUN in spite of challenging circumstances" (CLC, 2011, p. 1). Play opportunities are customized and integrated into the patients' care schedules and coordinated with the greater care team (MacDougall, Oldham, \& Cassman, 2008).

According to the American Academy of Pediatrics (2014), the provision of child life services is a benchmark of quality and excellence in hospitals that offer pediatric care. Research suggests that child life services improve quality and outcomes in pediatric care, as well as the patient and family experience (AAP, 2014). Satisfaction reports from patients, their families, and interdisciplinary medical team members suggest positive effects of child life programming in psychological and physiological realms (AAP, 2014). In one study, parents of children receiving 
WEINBERGER ET AL.

Playrooms serve as a refuge for children, and while the absence of medical tests and procedures in playrooms sets the stage, playrooms can be more than a shelter from medical intervention.

liver transplants reported that play-therapeutic interventions promoted coping skills and decreased fear of hospitals (Gold, Grothues, Jossberger, Gruber, \& Melter, 2014). Other studies have revealed physiological benefits associated with child life interventions, including less autonomic nervous system stimulation, reduced blood pressure change, less need for sedation, and less self-reported pain during and after medical procedures (Broome, Rehwaldt, \& Fogg, 1998; Ellerton \& Merriam, 1994; Stefanatou \& Bowler, 1997).

A growing body of research supports the work of child life professionals and validates the importance of play for hospitalized children. Therefore, it is prudent to understand how the design of hospital playrooms can best support the goals of over 400 child life programs that operate in North America alone (AAP, 2014). According to the CLC Values Statement, child life professionals embrace the value of play as a healing modality and note play's therapeutic role in facilitating "healing, coping, mastery, self-expression, creativity, achievement, and learning" (CLC, n.d.). The vision in the CLC Strategic Plan also indicates that child life specialists "advocate for play, self-expression, and other therapeutic interventions that minimize stress and maximize coping for children and families" (CLC, 2012). The hospital playroom is an environment that should be optimized to support the goals and values of child life professionals.

The purpose of this study was to identify and apply the expertise of child life specialists to reveal their perspective about important features of hospital playrooms (see Figures (1-5) for playroom photographs). Playrooms serve as a refuge for children, and while the absence of medical tests and procedures in playrooms sets the stage, playrooms can be more than a shelter from medical intervention. However, there is currently little research providing guidelines for how to create exemplary playrooms.

Developmental psychologist and design expert Anita Olds was the first to provide design guidelines for diverse children's healthcare spaces that specifically focused on keeping pediatric patients' unique needs in mind. Notably, Olds's wisdom is consistent with the primary values of child life. She reminds us that "a healthcare environment can be maximally effective when it affirms the capacity of children to heal themselves," and she identifies four ways that designers can create environments that nurture children (Olds, 1991, p. 112). Olds suggests that designers should: (1) maximize the capacity of children to move about freely in their space; (2) create environments in which children feel comfortable; (3) create opportunities for children to feel a sense of competence and mastery; and (4) arrange furniture in such a way that children feel safe, secure, and in control (Olds, 1991). Olds also recommends that all play spaces for children include opportunities for six types of activities: quiet activities (e.g., reading books, solving puzzles), gross motor activities (e.g., sliding, climbing), craft activities, dramatic play, games, and therapeutic activities (p. 114).

Documenting the impact of the physical environment in pediatric healthcare settings has become an increasingly important priority for environmental design researchers over the last 20 years. In the early 1990s, healthcare architects began to seek empirical data to influence the design of healthcare settings. However, many studies existing at the time lacked the methodological rigor required to be useful for generating design guidelines, and only a few focused on pediatric environments, most commonly neonatal intensive care units (NICUs) (Shepley, 2001). Healthcare Environments for Children and Their Families was published in 1998 and highlighted the needs of children and families in healthcare settings: privacy and personalization of space, distraction, supervision by staff, age-appropriate environments, family supportive spaces, and healing sensory dimensions (Shepley, 2001; Shepley, Fournier, \& McDougal, 1998). At the time, it was clear that there was a need for more studies focused on children and pediatric environments. Shepley noted that children are likely to be especially susceptible to the environment and cautioned that findings pertaining to the impact of healthcare environments on adults will not always generalize to pediatric patients. 


\section{Figure 1. Study images of Simon's main playroom}
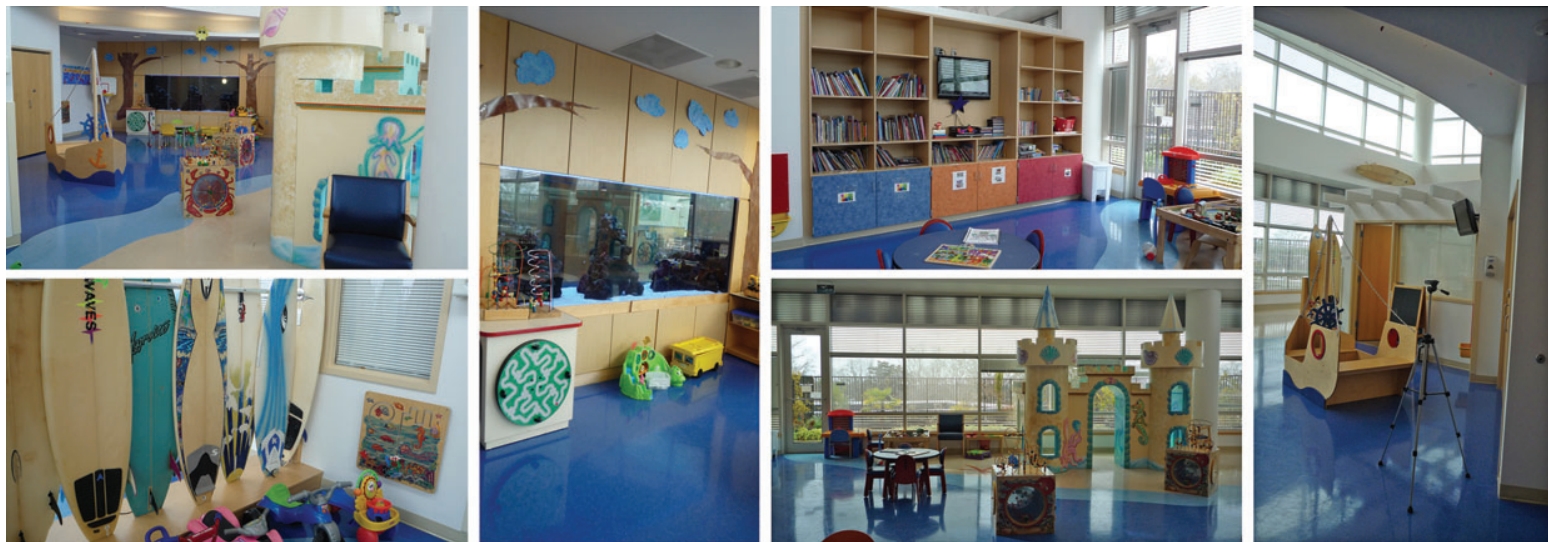

Figure 2. Study images of Henderson's main playroom

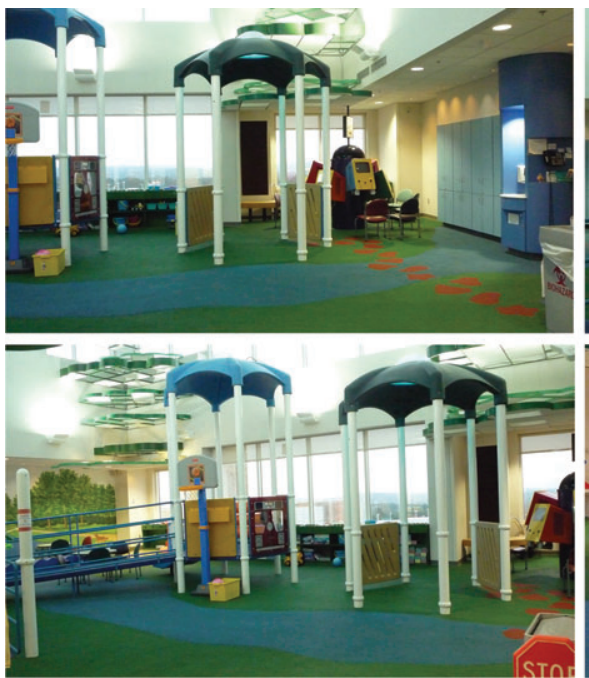

The new millennium brought an unprecedented rise in the construction and renovation of healthcare facilities and a heightened interest in evidence-based facility design, or "the deliberate attempt to base building decisions on the best available evidence with the goal of achieving the best possible outcomes for parents, families, and staff..." (Sadler \& Joseph, 2008, p. 2). A report from the National Association of Children's Hospitals and Related Institutions synthesized findings from more than
200 studies to demonstrate a variety of ways by which the physical environment of pediatric healthcare settings significantly impacts the experiences and outcomes of children and their families. In the report, Sadler and Joseph recommend evidence-based design strategies to improve children's outcomes, such as providing access to nature through gardens, designating age-appropriate play areas, providing positive distractions (e.g., virtual reality games, artwork with nature images), creating attractive spaces 
Figure 3. Study images of Baker's main playroom
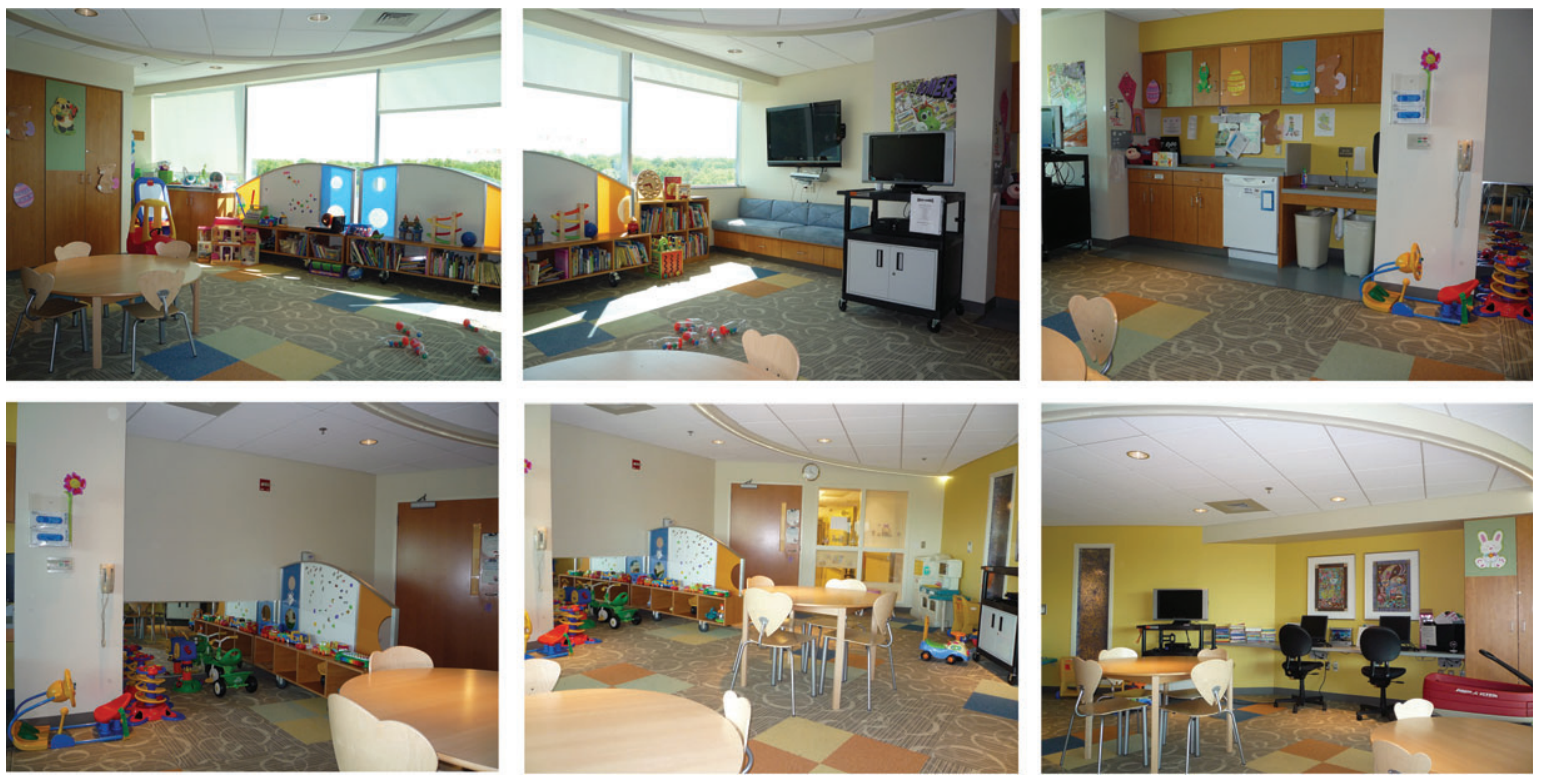

Figure 4. Study images of Parkman's main playroom
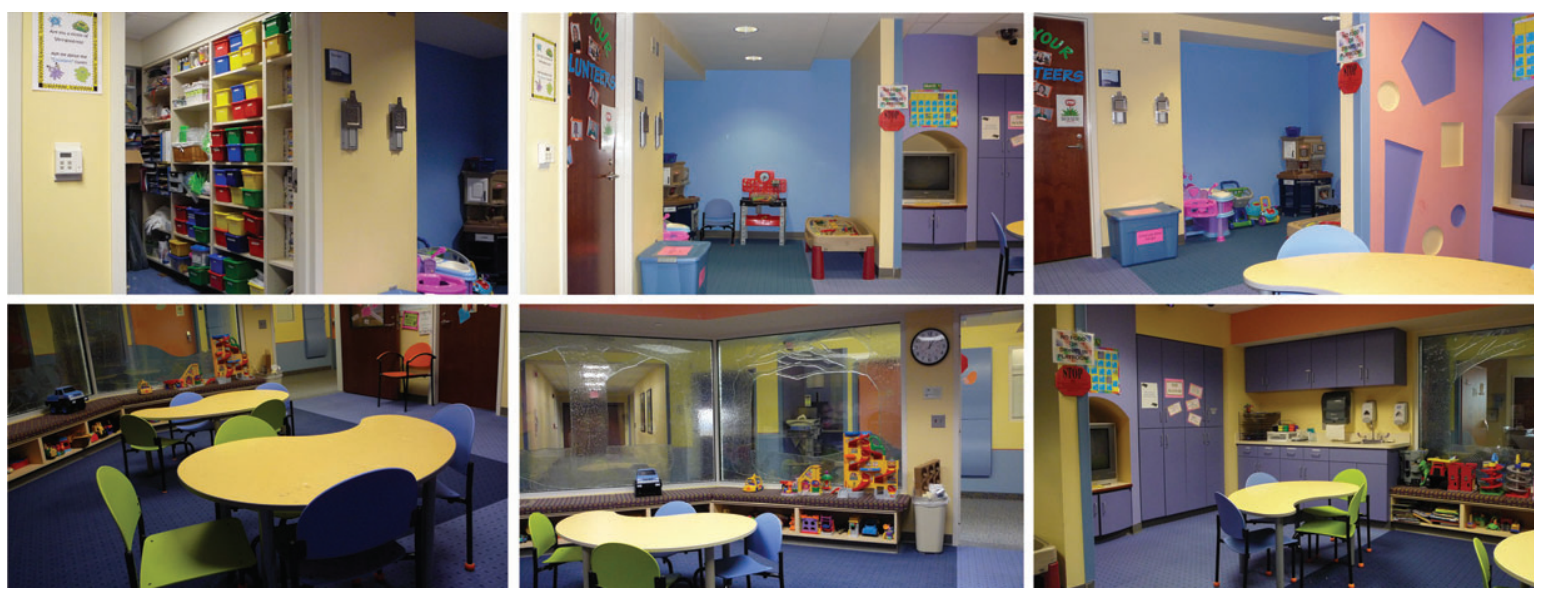

and a pleasant ambience, and providing access to natural light.

Recent research on healthcare environments demonstrates how aspects of specific interior spaces, such as hallways, lobbies, waiting areas, NICUs, and patient rooms, significantly influence the perceptions and experiences of hospitalized children and their families (Adams, Theodore, Goldenberg, McLaren, \& McKeever, 2010; Biddis, McPherson, Shea, \& McKeever, 2013; Sadler \& Joseph, 2008). Studies also reveal that children and adolescents have clear preferences in terms of the design and features of hospital settings in which they spend time (Coad \& Coad, 2008; Coyne 
WEINBERGER ET AL.

Playrooms are complex pediatric settings with many features that should be examined in the interest of evidence-based design.

Figure 5. Study images of Wheeler's main playroom
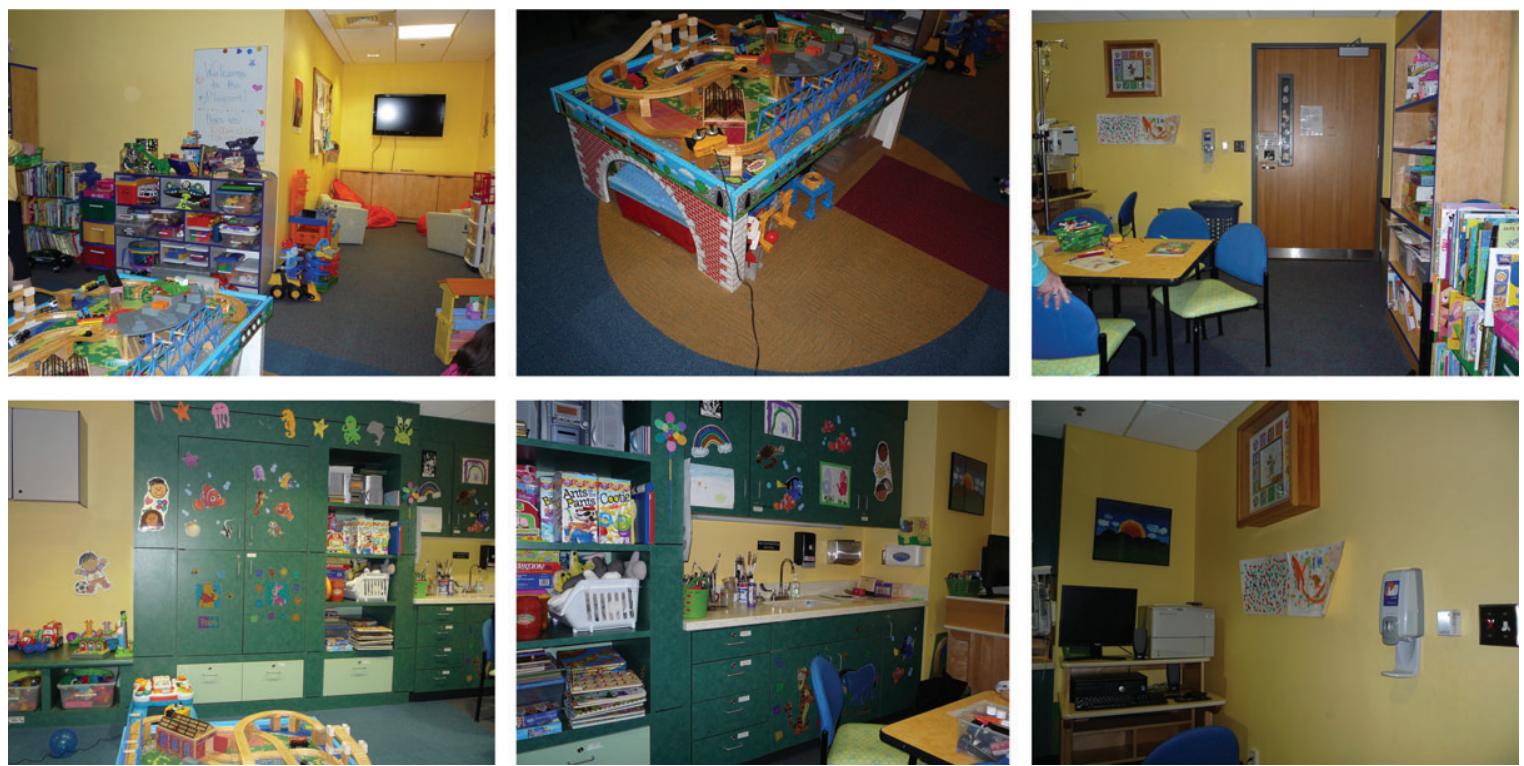

\& Kirwan, 2012; Park, 2009). For example, Blumberg and Devlin (2006) found that adolescent patients like bright colors in hospital hallways and lobbies, but they dislike childish emblems such as balloons and teddy bears.

In one study that focused on a hospital playroom specifically, Hosseinpour and Memarzadeh (2010) investigated the use of a preoperative playroom to prepare children for surgery. They reported that children who spent time in a hospital playroom prior to surgery displayed lower levels of behaviorally expressed anxiety and emotional distress than children who stayed in an ordinary patient waiting area. While this research suggests that a playroom environment has developmental and health benefits for children facing medical procedures, a more thorough examination of the specific features and design of hospital playrooms is warranted in order to understand how spaces can be created to meet the goals of child life.

Unlike patient rooms, NICUs, and waiting areas, the hospital playroom has not been a significant focus of healthcare design research to date. Yet, studies reveal therapeutic benefits of providing play spaces for children receiving medical treatment and highlight the importance of age-appropriate play areas (Sadler \& Joseph, 2008). Playrooms are complex pediatric settings with many features that should be examined in the interest of evidence-based design. Attributes of hospital playrooms include sensory dimensions (e.g., light/windows, color, décor, sound), physical dimensions (e.g., spaciousness, storage, organization, flooring), safety dimensions (e.g., cleanliness, accessibility), and play-related dimensions (e.g., play options, age-specific play zones), among other aspects.

One important dimension on which child life playrooms vary that may not be especially salient to child life specialists is the presence of biophilic design attributes (McGee, 2012). Biophilic features are those that appeal to humans' inherent affinity for nature. These elements could include, for example, the presence of plants and animals, the simulation of forms found in nature, connections to the locality, sense of place, and other spatial and lighting features that evoke a feeling of being in a natural environment 
(Kellert, 2008; McGee \& Marshall-Baker, 2015). In a study of young children's perspectives of ideal design features in hospital environments, children valued the inclusiveness of flora and fauna in décor, as well as esthetic window views to the outside world (Lambert, Coad, Hicks, \& Glacken, 2014). Other studies have shown that the developmental health of children improves when they are able to play in biophilic environments (e.g., Kellert, 2008; Louv, 2008). Therefore, biophilic features should also be considered in the design of child life playrooms.

Biophilic features identified by Kellert (2008) are the basis for the Biophilic Design Matrix (BDM), which is useful in child life and healthcare contexts (McGee, 2012). Environments can be analyzed using the BDM in order to capture the variety and extent of biophilic attributes present. McGee's use of the BDM to assess 24 child life playrooms on biophilia showed considerable variation among the spaces. In the study, around $30 \%$ of child life specialists expressed a desire or appreciation for nature-based design features (McGee, 2012, p. 55).

It is clear that hospital spaces designated for children will vary in terms of design, and staff who use the spaces are likely to have certain preferences about these settings. However, there is minimal research on child life specialists' perceptions of hospital playrooms and no research on how playrooms can be designed to support explicitly child life goals. This study used a photograph-based methodology to address whether the current state of playroom design is viewed as supportive of child life specialists' professional goals and values.

The photo method was chosen because it allows participants to rate easily real-world spaces depicted in a series of photographs (Blumberg \& Devlin, 2006; Weinberger, Butler, \& Schumacher, 2013). Roth (2006) evaluated a photo-based methodology in his study of visual landscape assessment and determined that-with the exception of peculiarity-landscapes were not evaluated significantly differently in person than when presented as photographs as part of an online survey. Nejati, Shepley, Rodiek, and Lee's
(2016) study of hospital staff break areas serves as a recent example of research utilizing photographs as a tool for healthcare professionals' assessment of the physical environment. Nurses were shown photographs of common types of break rooms and asked to rate their effectiveness for promoting stress relief and restoration. The current study addresses a need to examine more thoroughly the efficacy of a photo-based methodology in research on settings that are otherwise difficult to access. McGee (2012) used a photo method in a study assessing biophilic variety in 24 child life hospital playrooms throughout the state of North Carolina. The present study uses five of these playrooms to examine whether a photo method can effectively capture child life specialists' detailed preferences for features of child life playrooms.

\section{The Current Study}

In addition to exploring the efficacy of using a photo-based methodology with child life specialists, the primary purpose of this research was to draw on their expertise in order to identify which elements contribute to the design of optimal playrooms for hospitalized children. Using a within-subjects design and survey methodology, this research addressed the following two research questions:

1. Are child life specialists able to use a photograph methodology to make fine distinctions among hospital playrooms?

2. When presented with photographs of hospital playrooms, which playroom features do child life specialists view most favorably?

\section{Method}

\section{Participants}

The researchers recruited child life specialists through a variety of channels. First, one of the researchers distributed hard copies of the invitation at the New England Child Life Professionals (NECLP) annual conference. The invitation was also sent out electronically through the CLC Forum, a CLC listserv 
representing an international child life professional organization. In addition, the invitation was posted to the Wheelock College Alumnae Association LinkedIn page as Wheelock College offers academic programs in child life. Finally, the researchers consulted the U.S. News and World Report of the Top 10 U.S. Hospitals (2014-2015) and sent the invitation to participate in the study to child life specialists at those ten hospitals located in cities across the country. Snowball sampling was also employed, where participants were encouraged to forward the invitation to other child life professionals whom they believed would be interested in taking part in the study

Participants included 90 child life specialists ranging in age from 22 to 62 years $(M=35.78 ; S D=10.87)$. The sample was predominantly female $(n=88)$. Most of the participants self-reported as White $(n=78)$; other participants identified as Black or African American $(n=4)$, Asian $(n=3)$, Hispanic/Latino $(n=1)$, Asian/White $(n=1)$, and Chicano $(n=1)$. Two participants did not report their ethnicity.

Participants had worked in the field of child life for a mean of 9.85 years ( $S D=8.82$; range $1-38$ years). A majority of the participants $(53.3 \%)$ have at least a master's degree. Others have a bachelor's degree $(45.6 \%)$ or an associate's degree $(1.1 \%)$. A total of $80 \%$ of participants work in a hospital playroom currently. In addition, $67.8 \%$ of the participants have provided input on the design of one or more child life playrooms in the past.

\section{Procedure and Survey Design}

An electronic survey was emailed to all eligible participants who contacted the researchers. The survey included multiple colored photographs of five playrooms, providing a thorough view of each playroom as seen in Figures 1-5. The order of the five playrooms was counterbalanced across surveys. The photographs of each playroom depict representative examples of actual hospital playrooms and were a subset of the photographs used in McGee's (2012) study. These playrooms were selected to differ from one another. The BDM scores from the McGee study were available to describe one way in which the playrooms differed and were therefore used in the current study. The average (BDM) score from McGee's study was 21.5 out of a possible 52, and the highest BDM score was 39. In the current study, playrooms were selected to have relatively high (i.e., 39 and 37), moderate (i.e., 25), and low (i.e., 18 and 19) BDM scores, as noted in Table 1. The selection was also based on receiving approval to reuse the images by each of the facilities for the current study. All rooms had their identities hidden and were assigned the pseudonyms: Simon, Henderson, Baker, Parker, and Wheeler.

The survey includes five parts.

In Part 1, participants were asked to report demographic and background information about their education and professional experience.

In Part 2, respondents were asked to look at the six photographs for each playroom before answering any questions. The aim was for participants to familiarize themselves with each of the playrooms before continuing with the survey.

In Part 3 of the survey, participants were presented with the same playroom photographs that were shown in Part 2. This time, after viewing each set of 6 playroom photos, the participants were presented with 14 playroom rating items (Q1-Q14). Each playroom rating item was a statement about the playroom that the participant rated on a 7-point Likert scale $(1=$ strongly disagree; $7=$ strongly agree). The items were derived from the analysis of the CLC's mission and goals statement (CLC, n.d.) and focused on the following themes: safety, coping, normalizing, social interaction, mastery, and play. See Table 1 for a listing of the playroom rating items included in the survey. The same set of survey items were presented after each set of playroom photographs.

In Part 4, participants were asked an open-response question about each playroom. They were still able to view the photographs of each space. Specifically, 


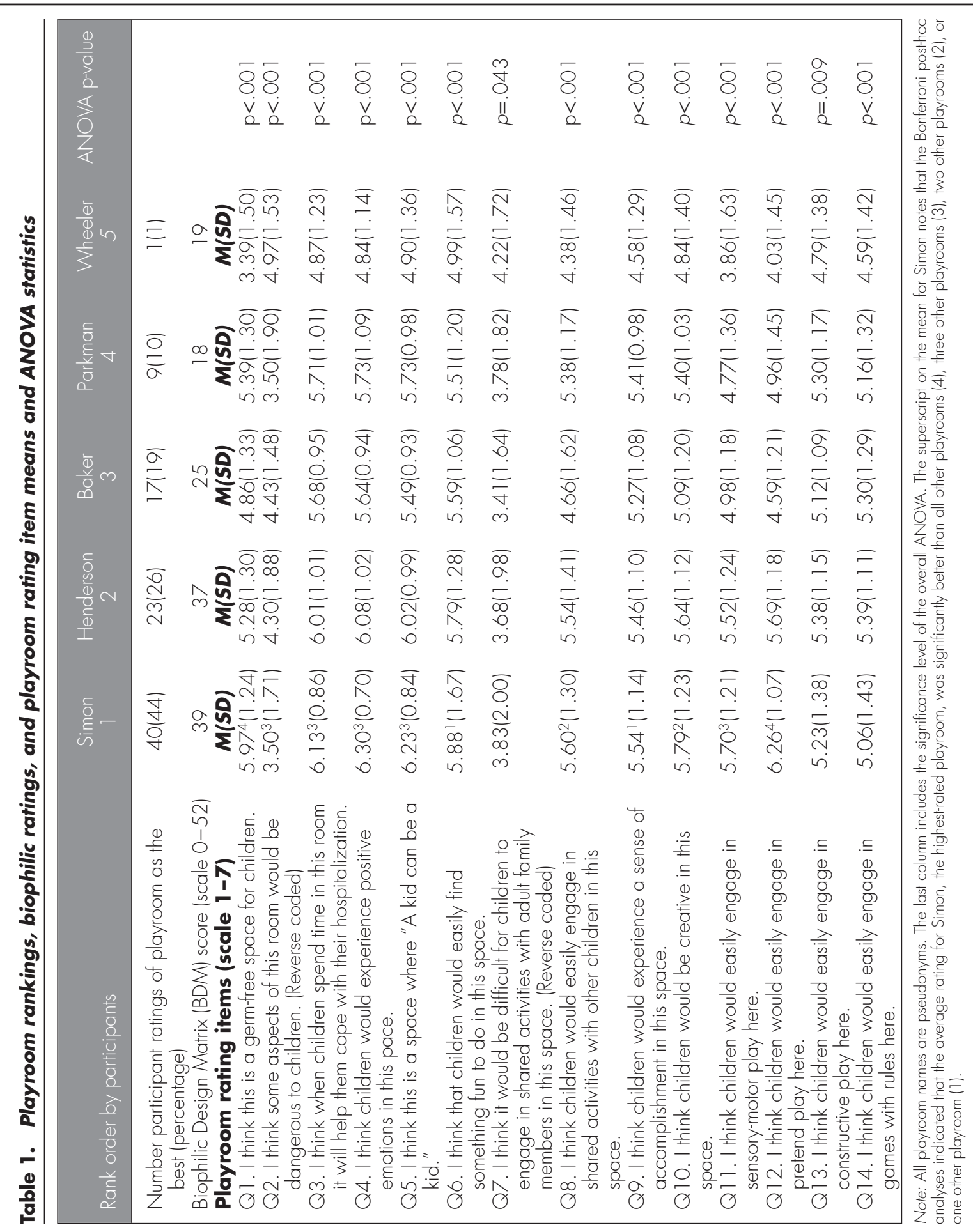


WEINBERGER ET AL.

Thereafter, a trained research assistant who was blind to the study research questions and did not see the playroom photographs or playroom names coded each specific item into one of 14 themes.

participants were instructed to "imagine yourself working in this playroom" and were asked "what do you like best about this playroom?" There was no word limit, and participants could comment on as many aspects of the space as they wished.

In Part 5, the sets of photos for each playroom were all shown again, and the participants were asked to rank the five rooms in order according to their ability to support child life goals. This section was included in an attempt to identify overall preference levels and to allow for a global comparison among the five playrooms.

Pilot testing suggested that survey completion took approximately 30 minutes. When submitting the survey electronically, participants provided their email address. Each participant was emailed a $\$ 15$ gift card from an online retailer as a token of appreciation for their participation in the study.

\section{Open-response Coding}

The open-response questions (Part 4) on what participants liked best about each playroom generated 887 open-response items to be coded. Participants were not limited in the number of comments they used to describe each playroom, and therefore, there were unequal numbers of discrete comments about each playroom. A coding system was developed based on the most frequently cited comments by the participants. The frequent comments were then grouped by common themes. Thereafter, a trained research assistant who was blind to the study research questions and did not see the playroom photographs or playroom names coded each specific item into one of 14 themes. In order to assess inter-rater reliability, the first author coded $17 \%$ of the comments without information that identified the playrooms. The two coders had $86 \%$ agreement in their coding selection of the open-response items. Following the coding, closely related coding themes were collapsed into 11 themes, as seen in Table 2.

\section{Results}

Q1: Are Child Life Specialists Able to Use a Photograph Methodology to Make Fine Distinctions Among Hospital Playrooms?

Based on playroom ranking and playroom rating results, it is clear that child life specialists made meaningful distinctions among the five playrooms. The participants ranked the playrooms according to how well they perceived their support of child life goals. The five playrooms appear in order from the highest to the lowest rank in Table 1 . It can be noted that Simon is clearly ranked the best overall by a majority of the participants (44\%), while Wheeler ranked last, with only one participant ranking it as the best.

Repeated measures analysis of variances (ANOVAs) were run for all 14 rating items. In all but four cases (Q2, Q4, Q7, and Q8), Mauchly's test indicated that the assumption of sphericity was violated, and therefore, the degrees of freedom for the overall F-test were subsequently adjusted using the Huyn-Feldt $(e \geq .75)$ correction. In all 14 cases, the null hypothesis of equal means was rejected, with 12 out of 14 ratings having a significance level less than .001 . The $F$-test values, $p$-values, and partial eta-squares $\left(\eta_{p}^{2}\right)$ for the overall ANOVA results are presented in the last column of Table 1 . These findings indicate that the participants were sensitive to distinctions among hospital playrooms.

Post-hoc analyses for pairwise differences were run with a significance level of .05 using a Bonferroni adjustment, and the individual means are also presented in Table 1. As Simon was clearly ranked the best playroom, it is used as the benchmark for reporting the pairwise differences among all playrooms. Thus, the pairwise differences are presented by noting significant differences between Simon and the other four playrooms. The superscript annotations associated with Simon's mean for each rating item indicate the number of playrooms whose means were significantly different from Simon. Simon has the highest average rating in 10 of the 14 playroom rating items and ties for the highest for an additional rating item. 
WEINBERGER ET AL.

The top valued design features include biophilic elements, appealing color and décor, and open space.

Table 2. Open-response frequencies and frequency percentages for best-liked playroom features

\begin{tabular}{|c|c|c|c|c|c|c|c|c|c|c|c|c|}
\hline \multirow[b]{2}{*}{ Nature elements } & \multicolumn{2}{|c|}{ Simon } & \multicolumn{2}{|c|}{ Henderson } & \multicolumn{2}{|c|}{ Baker } & \multicolumn{2}{|c|}{ Parkman } & \multicolumn{2}{|c|}{ Wheeler } & \multicolumn{2}{|c|}{$\begin{array}{l}\text { Frequency and } \\
\text { percentage } \\
\text { by themes }\end{array}$} \\
\hline & 59 & $28 \%$ & 60 & $29 \%$ & 41 & $23 \%$ & 14 & $8 \%$ & 0 & $0 \%$ & 174 & $20 \%$ \\
\hline Color and décor & 37 & $17 \%$ & 40 & $20 \%$ & 20 & $11 \%$ & 44 & $25 \%$ & 25 & $22 \%$ & 166 & $19 \%$ \\
\hline Open space & 38 & $18 \%$ & 43 & $21 \%$ & 22 & $12 \%$ & 10 & $6 \%$ & 1 & $.8 \%$ & 114 & $13 \%$ \\
\hline Play options & 34 & $16 \%$ & 23 & $11 \%$ & 14 & $8 \%$ & 15 & $9 \%$ & 30 & $26 \%$ & 116 & $13 \%$ \\
\hline Storage and organization & 11 & $5 \%$ & 8 & $4 \%$ & 5 & $3 \%$ & 51 & $29 \%$ & 22 & $19 \%$ & 97 & $11 \%$ \\
\hline Zones & 7 & $3 \%$ & 18 & $9 \%$ & 37 & $20 \%$ & 19 & $10 \%$ & 13 & $11 \%$ & 94 & $10 \%$ \\
\hline Cleanliness & 14 & $7 \%$ & 5 & $2 \%$ & 19 & $10 \%$ & 10 & $6 \%$ & 10 & $9 \%$ & 58 & $7 \%$ \\
\hline Media & 3 & $1 \%$ & 1 & $.4 \%$ & 16 & $9 \%$ & 2 & $1 \%$ & 5 & $4 \%$ & 27 & $3 \%$ \\
\hline Flooring & 8 & $3 \%$ & 3 & $1 \%$ & 4 & $2 \%$ & 2 & $1 \%$ & 0 & $0 \%$ & 17 & $2 \%$ \\
\hline Accessibility & 3 & $1 \%$ & 3 & $1 \%$ & 3 & $2 \%$ & 2 & $1 \%$ & 5 & $4 \%$ & 16 & $2 \%$ \\
\hline Safety & 0 & $0 \%$ & 0 & $0 \%$ & 1 & $.5 \%$ & 4 & $2 \%$ & 3 & $3 \%$ & 8 & $1 \%$ \\
\hline Frequencies by playroom & 214 & & 204 & & 182 & & 173 & & 114 & & 887 & $101 \%$ \\
\hline
\end{tabular}

Note: All playroom names are pseudonyms. Due to rounding, the percentages do not always add to $100 \%$. Examples from participants for each theme are noted here: nature elements (e.g., window view), color and décor (e.g., bright colors), open space (i.e., spaciousness), play options (e.g., gross motor choices), storage and organization (e.g., not cluttered), zones (e.g., specified area for teens), cleanliness (e.g., dishwasher), media (e.g., computers), flooring (e.g., soft carpet), accessibility (e.g., room for wheelchairs at the table), and safety (e.g., easy to supervise).

\section{Q2: When Presented with Photographs of Hospital Playrooms, Which Playroom Features do Child Life Specialists View Most Favorably?}

The findings indicate that child life specialists favor playrooms with specific design features and playrooms that support the values of the child life profession. The top valued design features include biophilic elements, appealing color and décor, and open space. Playrooms that support child life values provide a positive emotional climate and have opportunities for meaningful play.

There is evidence from two sources that child life specialists prefer playrooms that include biophilic design elements. The first source of support is that the playroom ranking order was consistent with the BDM scores assigned by McGee (2012). Simon and Henderson were highly ranked and had higher BDM scores (39 and 37, respectively, out of a possible 52 ), and Baker was ranked in the middle and had a moderate BDM score of 24, whereas Parkman and Wheeler, the lowest-ranked playrooms, had lower BDM scores of 18 and 19 , respectively.
Second, the importance of biophilic features was confirmed by the qualitative descriptions of what was liked best about the playrooms. All of the participants' discrete descriptions $(n=887)$ were coded into 1 of 11 themes. As seen in Table 2, the top theme that emerged was nature elements $(20 \%$ of all comments). The most frequently noted nature elements were having windows or daylight in the room. Importantly, while nature elements are frequently cited as best-liked features in highly and moderately ranked playrooms, low-ranked playrooms either infrequently $(8 \%)$ or never mentioned nature elements.

Two of the remaining highly valued design features were revealed in the open-ended responses about best-liked features, and they were appealing color and décor $(19 \%)$ and open space $(13 \%)$. Open space, like nature elements, was frequently cited as a best-liked feature for high- and middle-ranked playrooms, but not for the two lowest-ranked playrooms.

Child life specialists also favor playrooms that support the values of the child life profession by having a positive emotional climate and offering opportunities for meaningful play. Positive emotional climate 
WEINBERGER ET AL.

With regard to our first research aim, the playroom ranking and ratings results clearly showed that child life specialists could detect subtle differences among five real-world hospital playrooms depicted in a series of photographs.

was evaluated in the following three rating items: Q3 ("help them cope with their hospitalization”), Q4 ("experience positive emotions"), and Q5 ("where a "kid could be a kid"”). As seen in Table 1, playroom rating results revealed that items reflecting positive emotional climate were among the highest playroom ratings, and this was especially the case for Simon (i.e., at least a $M$ of 6.13 out of 7 ).

Another important child life professional value is the provision of meaningful play. Therefore, it is not surprising that child life specialists rated pretend play and sensory play highly. Moreover, as seen in Table 1, Simon's ratings for pretend play $(M=6.26)$ were significantly higher than all other playrooms, and sensory play $(M=5.70)$ was higher than three other playrooms. In addition, among best-liked features, play options was tied as the third most frequently cited theme across playrooms $(13 \%)$.

\section{Discussion}

The present study examined child life specialists' perceptions of hospital playrooms. Previous studies have shown how certain hospital environments, such as intensive care units, patient rooms, and waiting areas, can improve the experiences and outcomes of hospitalized children and their families (Adams et al., 2010; Biddis et al., 2013, Choi \& Bosch, 2013). However, there is a notable lack of research focused on hospital playrooms and how they can be designed to support the mission of child life.

The current study addresses this gap with two research aims. First, it examined whether child life specialists were able to use a photograph analysis procedure to make fine distinctions among real-world hospital playrooms. Second, this study explored the hospital playroom features that child life specialists prefer given their professional values and the goals of child life.

\section{Photograph Analysis}

With regard to our first research aim, the playroom ranking and ratings results clearly showed that child life specialists could detect subtle differences among five real-world hospital playrooms depicted in a series of photographs. For example, when asked to order the playrooms according to how well they supported child life goals, Simon was ranked as the best most often, while Wheeler was ranked the best by only $1 \%$ of the participants. Also, significant differences were observed in all 14 playroom rating means across different playrooms. Furthermore, the rich qualitative descriptions reflected the keen ability to notice fine distinctions, as well as professional expertise and deep investment in conducting a detailed examination. To illustrate, a participant commented about Simon:

I really like that the flooring is easy to clean, and not likely to trip anyone. The natural light and windows are awesome. There is a lot of storage available in the cabinets. There is an area with a TV and hopefully a gaming system. The fish tank is always a pleasing visual item. I also like the different themes that are established with the surf boards and the castle, etc. I think children enjoy seeing themes that they relate to and like, and want to be in those spaces.

Such detailed assessments of each playroom indicate that child life specialists can provide a wealth of information for research and design purposes.

Photograph-based methodologies have emerged in environmental design research as a way to survey efficiently participants' preferences and perceptions of real-world spaces, such as house and building facades, psychotherapists' offices, and child care spaces (Akalin, Yildirim, Wilson, \& Kilicoglu, 2009; Devlin, 2008; Devlin \& Nasar, 2012; Weinberger et al., 2013). With limited research specifically on the hospital playrooms, using a methodology that allowed for a comparison of many different playrooms at once by the same group of child life specialists was particularly valuable. Given the sensitive and private nature of medical-related issues and hospitalization, especially pertaining to children, it would have been nearly impossible for the participants to see multiple playrooms in person. Indeed, there was 
WEINBERGER ET AL.

The deliberate amalgamation of color, light, and décor in hospital settings can cue certain behaviors and cognitions, influence the quality of experiences, and facilitate healthy development (Tofle, Schwarz, Yoon, Max-Royale, \& Des, 2004).

a clear rationale for employing a photograph-based methodology in the current study, and given its successful application here, it should be considered a useful approach for future hospital-based research with healthcare professionals.

\section{Preferred Playroom Features}

With regard to the second research aim, child life specialists favor playrooms that have biophilic elements, pleasing color and décor, and open space. While both cleanliness and safety are integrated in all of the playrooms, they are only cited as best-liked features in the absence of these more eye-catching features. The current study shows the value of biophilia in child life play spaces, specifically windows, light, and nature themes. These features were identified the most in the highest-rated playrooms and omitted entirely in the lowest rated playroom. This is evidently an important specification to add to Old's list of features for environments that nurture children. Prior biophilia research results have reported reduced behavioral conduct disorders, anxiety, and depression (Wells \& Evans, 2003); restoration of attention (Herzog, Black, Fountaine, \& Knotts, 1997); and increased cognitive function (Wells, 2000) when people experience nature. Consistent with these results, the current findings show nature elements as the most preferred feature type in the interior (e.g., a park-themed wall mural). This may show an implicit knowledge that child life specialists have for nature supporting the pediatric healing process. Interestingly, the data may even underestimate the value of biophilia. Color, open space, and components of décor are also labeled as attributes of biophilic design by Kellert (2008), yet they are itemized separately in the current study. The thoughtful inclusion of a diversity of biophilic features can thus be an important goal for playroom designs and future research. Each of the specific feature categories is discussed in detail below.

\section{Nature Elements}

The child life specialists listed daylight and windows as frequent exemplars within the nature elements category. Windows provide access to daylight in the interior, and they have been shown to influence positively health outcomes within healthcare settings (Benedetti, Colombo, Barbini, Campori, \& Smeraldi, 2001; Joseph, 2006; Sadler \& Joseph, 2008; Ulrich, 1984). While nature views may not be available inside every healthcare setting, the addition of daylight is important "not only because it is beneficial to patients and staff, but also because it is light delivered at no cost and in a form that most people prefer" (Joseph, 2006, p. 1). Natural views benefit both children and adults and should be considered a high priority when planning playroom design and location. One participant stated about Simon, "The large windows let in a lot of natural light." Another participant noted Simon's windows this way, "Windows! Looks outside at trees and grass."

\section{Color and Décor}

Florence Nightingale (1859) wrote that the "variety of form and brilliancy in color of objects presented to patients are actual means of recovery" (p. 58). More than a century later, in the current study, child life specialists echo her sentiment by identifying color and décor as some of their highest-valued features. Specifically, color and décor were cited second most frequently as the child life specialists' best-liked features. As color is only visible with the addition of light, color and light are vitally important for pleasant hospital experiences (Dalke et al., 2006). The deliberate amalgamation of color, light, and décor in hospital settings can cue certain behaviors and cognitions, influence the quality of experiences, and facilitate healthy development (Tofle, Schwarz, Yoon, Max-Royale, \& Des, 2004). Yet, it must be studied in context as spatial impressions are influenced by contrast effects, saturation, and differences between adjacent objects and the foreground (Tofle et al., 2004). Kellert (2008) describes the importance of color as a component of biophilia; we are naturally drawn to color (e.g., natural colors found in bright flowers, rainbows, and sunsets). Participants' comments about color and décor also fit with Olds's (1991) characterization of design helping children be more comfortable and Sadler and Joseph's (2008) recommendation for attractive spaces and pleasant ambience in children's 
WEINBERGER ET AL.

\section{Well-designed playrooms with engaging imaginative features and storage for props and accessories can} support rich pretend play experiences for children.

healthcare settings. A participant commented that in Simon, the "colors in the room are inviting for children," and another participant described the color for highly ranked Henderson in this way, "I love the color palate. It is very calming." A comment about its décor included, "The area looks like water with the painting of the sailboat on the wall." Care in selecting color and décor for children's spaces should rely on research-supported choices that take age, gender, and cultural dimension differences into account (Coad \& Coad, 2008; Park \& Park, 2013).

\section{Open Space}

Open spaces were tied for the third best-liked feature by child life specialists. Open spaces allow for traffic and activities to occur without crowding. A participant described Simon as spacious and commented that it "leaves room for exploration and manipulation." Olds (1991) also highlighted spaciousness and remarked that it can nurture healing with the capacity for children to move about freely in a healthcare environment. While adults may prefer open rooms for different reasons than children, recent research showed that adults were more likely to rate such spaces as beautiful (Vartanian et al., 2015). Enclosed spaces were more likely to elicit exit decisions; they created an emotional discomfort that made people want to leave (Vartanian et al., 2015). Notably, open space has also been reported as a valuable component in other settings for children, namely child care homes and centers (Weinberger et al., 2013). Child care providers considered open space to be the most crucial design feature that supported physical activity for young children.

\section{Play Options}

In the current study, availability of play options was frequently cited among features that were best liked by child life specialists. This is consistent with Olds's (1991) mandate to create opportunities for children to feel a sense of competence and mastery through appropriate play choices. The child life specialists in the current study indicated that the best ranked playroom had high ratings of pretend play and sensory-motor play in particular. This result underscores a surprising finding from Vilas's (2014) report for the CLC in which 181 child life programs were reviewed. Sensory-motor play and pretend play options were not among the most frequent offerings and led to CLC recommendations to increase access to pretend play and sensory play. The participants in the current study would likely concur about improving sensory-motor and pretend play options given their favorable ratings. One quote about Simon highlights this: "There is a lot of room and lots of props for pretend play. It also encourages children to imagine that they are somewhere else besides the hospital with the props (castle and boat)." A critique of the same space cited that there were no visible "toys to encourage more pretend play with the boat and castle structure already there such as costumes." Well-designed playrooms with engaging imaginative features and storage for props and accessories can support rich pretend play experiences for children.

\section{Storage and Organization}

In order to support these and other activities, child life specialists are mindful of the need for storage and good organization. Children need visible choices to make it clear that in this domain, they are able to gain back some sense of control. One participant liked that the Parkman playroom had "significant storage space for play items to keep floors uncluttered." This organization allows for greater options and greater open floor space for safer travel paths/circulation. This can be a challenging balance, but abundant storage, both accessible and controlled/locked access, was listed as a priority to provide developmentally appropriate choices to patients. Too much disorganization makes the space seem messy and a "sensory overload" as some participants commented about one of the spaces. The use of bins or open shelving helps to keep things organized but gives visual access to toys and games for children. Mastery and competence can also be achieved through access to choice. As one participant noted, "I also like the shelving and how it is low for little ones to be able to reach and pull their own toys out." 
WEINBERGER ET AL.

Maneuverability was a key safety issue and ties to the special populations that use these spaces.

\section{Zones}

Zoning allows multiple activities that are appropriate for diverse ages to occur simultaneously. Shepley (2001) and Sadler and Joseph (2008) both recommended designating age-appropriate play spaces to improve the experiences and outcomes of children in healthcare settings. While this feature was less frequently noted than open spaces in the current study, participants often highlighted the need for defined areas for infants that included soft and washable mats and were safely out of the traffic pattern. The separation of adolescents was another repeated comment. For example, one participant described a best-liked feature of Wheeler to be that it had a "separate area for older school-age children and teens."

As well as the design features that child life specialists prefer in hospital playrooms, the emotional climate of the setting and the types of play that children engage in also emerged as important elements for the participants. According to the CLC, a core competency for child life specialists is to be able to arrange a "safe, therapeutic and healing environment for infants, children, youth and families" (CLC, 2015, p. 2). Our results indicate that if a playroom is a place where children can have positive emotions, build coping skills, and feel free to be themselves, then the playroom is seen as an optimal healing environment. None of this is possible without a safe, clean, and accessible environment. These findings are consistent with Olds's (1991) recommendations that designers should aim to create environments in which children feel comfortable and arrange furniture in such a way that children feel safe and secure. They also echo Shepley's (2001) emphasis on the importance of healing sensory dimensions in pediatric healthcare settings. The mainstay in establishing such a positive emotional climate involves the provision of play opportunities (Vilas, 2014).

\section{Safety, Ceanliness, Accessibility, Media, and Flooring}

Although safety was cited as a best-liked feature in only 8 of 887 responses, it is clearly a requirement for a hospital playroom that is designed for sick children. In fact, seven of the eight responses that named safety as a best-liked feature were for the two lowest-ranked playrooms. It was not, however, cited at all as a best-liked feature in the top two ranked rooms, perhaps not because it was absent but possibly because there were more interesting and attractive features to note. Additionally, when considering the playroom rating data, Simon, the highest-ranked playroom overall, was also rated the highest on the question referring to the safety of the room. The lowest-ranked playroom had the worst rating on this question. Maneuverability was a key safety issue and ties to the special populations that use these spaces. This is demonstrated in a comment about Simon noting that "I think the boat is cute, but would be difficult for wheelchairs and IV poles to maneuver [sic]. Could be a hazard." Safety was also tied to visual connections to the rest of the hospital as noted in a comment about Parkman: "Colorful-open windows to unit/hallways is good for safety."

Cleanliness is also a requirement for hospital playrooms, and yet it only accounts for 7\% (58 out of 887 ) of the comments about best-liked features, which are evenly distributed among the playrooms. It is worth noting that for the rating item on cleanliness, Simon is again rated the highest, and the lowest-ranking playroom is again rated the lowest. Among the comments about cleanliness was the repeated mention about having a dishwasher, as noted here about Baker: "I like the fact that there is a dishwasher for sterilizing toys." Additionally, tying cleanliness into safety and accessibility were noted, with one person stating they liked the "Sink to wash hands, toys, and paint brushes without having to leave the room."

Accessibility is a third required feature of hospital playrooms, and yet, it was cited in only $2 \%$ (16 out of 887) of the comments of best-liked features. Each playroom included comments noting the perceived accessibility, including liking the child-sized features or the features being either controlled by adults or easily accessed by children on their own. 
Table 3. Best-liked features with design strategies

\begin{tabular}{|c|c|c|c|c|}
\hline Best-liked feature & Components & Examples & $\begin{array}{l}\text { Comments from } \\
\text { child life professionals }\end{array}$ & Design strategies \\
\hline \multirow[t]{2}{*}{ Nature elements } & $\begin{array}{l}\text { Windows and } \\
\text { daylight }\end{array}$ & Clearstory windows & $\begin{array}{l}\text { "The windows make it } \\
\text { feel like [they] aren't } \\
\text { constantly trapped } \\
\text { inside all day" }\end{array}$ & $\begin{array}{l}\text { - Large windows with } \\
\text { a view of nature }\end{array}$ \\
\hline & Biophilic features & $\begin{array}{l}\text { Park-themed wall } \\
\text { mural }\end{array}$ & $\begin{array}{l}\text { "I like the soothing } \\
\text { ocean/water themed } \\
\text { elements and the } \\
\text { natural light" }\end{array}$ & $\begin{array}{l}\text { - Variety of natural } \\
\text { features, use of } \\
\text { natural theme }\end{array}$ \\
\hline \multirow[t]{2}{*}{ Color and décor } & Color scheme & Multicolor walls & $\begin{array}{l}\text { "I like the open, bright } \\
\text { feeling of the room and } \\
\text { the interesting structures } \\
\text { that could encourage } \\
\text { imagination" }\end{array}$ & $\begin{array}{l}\text { - Color integrated into } \\
\text { theme and } \\
\text { age-appropriate }\end{array}$ \\
\hline & Themed decorations & Castle structures & $\begin{array}{l}\text { "Awesome mural and } \\
\text { furnishings to promote } \\
\text { imaginative play" }\end{array}$ & $\begin{array}{l}\text { - Décor focused on } \\
\text { play opportunities }\end{array}$ \\
\hline \multirow[t]{2}{*}{ Open space } & Lack of clutter & Clear floor space & $\begin{array}{l}\text { "Open, spacious. It looks } \\
\text { very inviting and } \\
\text { engaging at first } \\
\text { glance" }\end{array}$ & $\begin{array}{l}\text { - Ample floor space } \\
\text { for circulation, } \\
\text { people, and } \\
\text { equipment }\end{array}$ \\
\hline & $\begin{array}{l}\text { Ability to play without } \\
\text { crowding }\end{array}$ & Wall-mounted features & $\begin{array}{l}\text { "Open space for } \\
\text { playing." }\end{array}$ & $\begin{array}{l}\text { - High ceilings to add } \\
\text { a sense of } \\
\text { spaciousness }\end{array}$ \\
\hline \multirow[t]{2}{*}{ Play options } & $\begin{array}{l}\text { Availability of pretend } \\
\text { play and } \\
\text { sensory-motor play }\end{array}$ & Costumes & $\begin{array}{l}\text { "This is another room that } \\
\text { is DISTINCTLY different } \\
\text { from all other hospital } \\
\text { rooms ... [with] creative } \\
\text { play options" }\end{array}$ & $\begin{array}{l}\text { - Visual access to } \\
\text { play choices }\end{array}$ \\
\hline & & Molding clay & $\begin{array}{l}\text { "Lots of options for } \\
\text { play/activities" }\end{array}$ & $\begin{array}{l}\text { - Variety of types of } \\
\text { play, organized to } \\
\text { be age-appropriate }\end{array}$ \\
\hline \multirow[t]{2}{*}{$\begin{array}{l}\text { Storage and } \\
\text { organization }\end{array}$} & Visible choices & Bins and shelving & $\begin{array}{l}\text { "Organization wall of } \\
\text { shelves seems like it is } \\
\text { helpful and organized" }\end{array}$ & $\begin{array}{l}\text { - Systematic storage } \\
\text { providing both easy } \\
\text { access to a variety } \\
\text { of play choices and } \\
\text { locked access for } \\
\text { controlled resources }\end{array}$ \\
\hline & $\begin{array}{l}\text { Prevent "sensory } \\
\text { overload" }\end{array}$ & Closets & $\begin{array}{l}\text { "Lots of storage, items for } \\
\text { a wide age range } \\
\text { available" }\end{array}$ & \\
\hline Zones & $\begin{array}{l}\text { Areas separated by } \\
\text { age or activity type }\end{array}$ & $\begin{array}{l}\text { Soft mats for infants } \\
\text { Tables of different } \\
\text { heights }\end{array}$ & $\begin{array}{l}\text { "Separation of different } \\
\text { places to play" } \\
\text { "I like that the room has } \\
\text { different areas for } \\
\text { different age groups" }\end{array}$ & $\begin{array}{l}\text { - Separate areas for } \\
\text { different age groups } \\
\text { - Furniture specified } \\
\text { for a variety of age } \\
\text { groups, including } \\
\text { adults }\end{array}$ \\
\hline
\end{tabular}

Note: The features are ordered from top to bottom based on having the most to the least number of participant comments among those listed here. 
WEINBERGER ET AL.

We recommend using a variety of color from the full palette found in nature and avoiding large planes of a single color to mimic the varied conditions found in nature.

A comment illustrating this was: "I like that appropriate and safe toys are on open shelving and easily accessible." Adult control over some of the resources was desired, with "the easily accessible storage area that can be closed to children" being appreciated in Parkman. Consistent with the comments about safety, accessibility was noted as a best-liked feature relatively more often for the lowest-ranked playroom as compared with the highest-ranked playroom. Therefore, cleanliness, safety, and accessibility are likely integrated in all of the playrooms and only cited as a best-liked feature in the absence of other valued features, such as nature elements, open space, color, and décor. The remaining features of media and flooring were infrequently noted as best-liked features. The comments that were coded for flooring were mostly about its sound absorbency or comfort as noted above. Media preferences addressed the availability of media for older children, such as this comment about Baker: "I like that there is a variety of media options for older children (computers, TVs)." A Parkman quote showed how having a media zone was desired: "I like the wall that divides the space where the TV is and the open play area for younger children." Thus, it appears that even less frequently cited features are meaningful to the participants in the current study.

\section{Implications for Practice}

The countless children who face chronic illness and hospitalization rely on child life services to mitigate the negative effects often associated with those experiences. The current study reveals that hospital playrooms are seen as supporting child life goals and that a variety of design features helps to create optimal playrooms. As seen in Table 3, noted design features and corresponding design strategy suggestions are provided. Moreover, we suggest that child life specialists rely on their collective expertise to advocate for such hospital playrooms. As a majority of the participants $(68 \%)$ responded that they had previously provided input on playroom design, their expertise is already being valued. It is important that design teams continue to include child life specialists when making design decisions for hospital playrooms. Also, photographs of existing spaces can be used to elicit meaningful feedback.

These findings suggest that child life specialists enthusiastically prefer playrooms with abundant biophilic features that encompass windows with nature views, a range of natural colors, appealing décor, and openness. Thus, it is not surprising that Wheeler, the playroom that was ranked the lowest by participants, was the playroom without any nature elements noted, and open space was only noted once as a best-liked feature. As a high priority, nature motifs and wide open spaces should be added when possible, as well as large windows to allow daylight in and offer views of nature. We recommend using a variety of color from the full palette found in nature and avoiding large planes of a single color to mimic the varied conditions found in nature. Moreover, it may be helpful to expand biophilic expression beyond nature motifs and consider the rich visual inventory of biophilic features available in attributes of the BDM (McGee \& Marshall-Baker, 2015). We have also discovered that the design elements valued by child life specialists easily coexist in playrooms that provide emotional support and, specifically, offer sensory-motor and pretend play options for hospitalized children. Thus, the findings from the current study indicate that among the many play options for hospitalized children, sensory-motor and pretend play options should always be available in the playrooms.

Reflecting the growing body of research on environmental design and human behavior, the Council for Interior Design Accreditation (CIDA) has recently updated their standards. The Professional Standards 2017 are used in evaluating interior design programs and parallel many of the findings here. Standard 7 Human-Centered Design now specifically lists biophilia as an aspect of the human-centered design standard (Council for Interior Design Education, n.d.). This update reflects the increasing body of literature that documents how representing nature in the interior promotes optimal well-being. The current study further supports how designers and educators can approach that goal. Standard 11 
WEINBERGER ET AL.

Playrooms that create a positive emotional climate and offer meaningful play opportunities for children receiving medical treatment align with the values of the child life profession.

Design Elements and Principles and Standard 12 Light and Color also have many parallels with the list of biophilic attributes and the preferences of the child life specialists for supportive play spaces.

\section{Limitations and Future Directions}

Child life specialists have expertise in child development and an understanding of how play spaces must accommodate the needs of hospitalized children. Yet, some may regard surveying only child life specialists as a limitation of the current study. Indeed, their view is not the only valuable perspective. For example, there is a need to understand thoroughly what hospitalized children and their parents value in the design of playrooms as well. A second limitation relates to the photograph methodology. As photographs do not capture any nonvisual aspects of the playroom environment, such as noise level or music, we were not able to examine these features, which are in need of further study (Sadler \& Joseph, 2008). Perhaps another limitation of this research is the sole focus on interior hospital playrooms. Child life specialists engage with pediatric patients in other areas of the hospital, including patient rooms and exterior play spaces. Moving forward, it will be important to include additional stakeholders in research to gather a truly comprehensive picture of what comprises the ideal hospital playroom. Future research could examine how the features and design of the full range of hospital play settings can also be optimized for child life.

\section{Conclusion}

This study provides evidence that a photo-based methodology is an effective and efficient strategy for the evaluation of hospital playrooms. Findings reveal that child life specialists prefer playrooms with specific design features and playrooms that support their professional values. The most favored design features include biophilic elements, appealing color and décor, and open space. Child life specialists value play as a healing modality and emphasize the important role of play in minimizing stress and maximizing coping for hospitalized children (CLC, 2012). Playrooms that create a positive emotional climate and offer meaningful play opportunities for children receiving medical treatment align with the values of the child life profession. Through incorporating the range of features identified in this research in practice and in education, playroom design can be seen through a clearer lens.

\section{References}

Adams, A., Theodore, D., Goldenberg, E., McLaren, C., \& McKeever, P. (2010). Kids in the atrium: Comparing architectural intentions and children's experiences in a pediatric hospital lobby. Social Sciences \& Medicine, 70(5), 658-667.

Akalin, A., Yildirim, K., Wilson, C., \& Kilicoglu, O. (2009). Architecture and engineering students' evaluations of house facades: Preference, complexity and impressiveness. Journal of Environmental Psychology, 29(1), 124-132.

American Academy of Pediatrics (2014). Child life services. Pediatrics, 133(5), el471-el478.

Benedetti, F., Colombo, C., Barbini, B., Campori, E., \& Smeraldi, E. (2001). Morning sunlight reduces length of hospitalization in bipolar depression. Journal of Affective Disorders, 62(3), $221-223$.

Biddis, E., McPherson, A., Shea, G., \& McKeever, P. (2013). The design and testing of interactive hospital spaces to meet the needs of waiting children. Health Environments Research \& Design Journal, 6(3), 49-68.

Blumberg, R., \& Devlin, A. S. (2006). Design issues in hospitals: The adolescent client. Environment and Behavior, 38(3), 293-317.

Broome, M. E., Rehwaldt, M., \& Fogg, L. (1998). Relationships between cognitive behavioral techniques, temperament, observed distress, and pain reports in children and adolescents during lumbar puncture. Journal of Pediatric Nursing, 13(1), $48-54$

Child Life Council. (201 1). Child life: Empowering children and families. Rockville, MD: Child Life Council. Retrieved August 1, 2012 from http://www.childlife.org/files/Flyer-ChildLife $2011 . p d f$

Child Life Council. (n.d.). Mission, values, and vision. Retrieved August 1, 2012 from http://www.childlife.org/The\%20Child $\% 20$ Life\%20Profession/ProfessionMissionVisionValuesPosition Statements.cfm

Child Life Council. (2012). Child Life Council strategic plan 20122014. Retrieved August 1, 2012 from https: / / www.childlife.org/ files/CLCStrategicPlan2012-2014.pdf

Child Life Council. (2015). Professional standards of practice: Child life competencies. Official documents of the Child Life Council. Retrieved December 15, 2015 from http://www.childlife.org/ files/ChildlifeCompetenciesUPDATED.pdf 
Choi, Y.-S., \& Bosch, S. J. (2013). Environmental affordances: Designing for family presence and involvement in patient care. Health Environments Research \& Design Journal, 6(4), 53-75.

Coad, J., \& Coad, N. (2008). Children's and young people's preference of thematic design and colour for their hospital environment. Journal of Child Health Care, 12(1), 33-48.

Council for Interior Design Education. (n.d.). Professional standards 2017. Retrieved October 10, 2016 from http://accredit-id. org/wp-content/uploads/2010/03/Professional-Standards2017-Jan_2016.pdf

Coyne, I., \& Kirwan, L. (2012). Ascertaining children's wishes and feelings about hospital life. Journal of Child Health Care, 16(3), 289-303.

Dalke, H., Little, J., Niemann, E., Camgoz, N., Steadman, G., Hill, S., et al. (2006). Colour and lighting in hospital design. Colour and Design in the Natural and Man-Made Worlds, 38(4-6), $343-365$.

Devlin, A. S. (2008). Judging a book by its cover: Medical building facades and judgments of care. Environment and Behavior, 40(3), 307-329.

Devlin, A. S., \& Nasar, J. L. (2012). Impressions of psychotherapists offices: Do therapists and clients agree? Professional Psychology: Research and Practice, 43(2), 118-122.

Ellerton, M. L., \& Merriam, C. (1994). Preparing children and families psychologically for day surgery: An evaluation. Journal of Advanced Nursing, 19, 1057-1062.

Gold, K., Grothues, D., Jossberger, H., Gruber, H., \& Melter, M. (2014). Parents' perceptions of play-therapeutic interventions to improve coping strategies of liver-transplanted children: A qualitative study. International Journal of Play Therapy, 23(3), $146-160$

Herzog, T. R., Black, A. M., Fountaine, K. A., \& Knotts, D. J. (1 997). Reflection and attentional recovery as distinctive benefits of restorative environments. Journal of Environmental Psychology, 17(2), 165-170.

Hosseinpour, M., \& Memarzadeh, M. (2010). Use of a preoperative playroom to prepare children for surgery. European Journal of Pediatric Surgery, 20(6), 408-41 1.

Joseph, A. (2006, August). The impacts of light on outcomes in healthcare settings. The Center for Health Design. Retrieved August 1, 2012 from https://www. healthdesign.org/sites/ default/files/CHD_Issue_Paper2.pdf

Kellert, S. (2008). Dimensions, elements, and attributes of biophilic design. In S. Kellert, J. Heerwagen \& M. Mador (Eds.), Biophilic design: The theory, science, and practice of bringing buildings to life (pp. 3-19). Hoboken, NJ: Wiley.

Lambert, V., Coad, J., Hicks, P., \& Glacken, M. (2014). Young children's perspectives of ideal physical design features for hospital-built environments. Journal of Child Health Care, 18(1), $57-71$

Louv, R. (2008). Last child in the woods: Saving our children from nature-deficit disorder. Chapel Hill, NC: Algonquin Books of Chapel Hill.
MacDougall, K., Oldham, D. B., \& Cassman, A. B. (2008). The benefits of a school teacher vs. a child life specialist serving pediatric patients on dialysis. Nephrology Nursing Journal, 35(4), 399-402.

McGee, B. (2012). An inventory of biophilic design attributes within child life play spaces. Unpublished doctoral dissertation, University of North Carolina at Greensboro, Greensboro, NC.

McGee, B., \& Marshall-Baker, A. (2015). Loving nature from the inside out: A biophilia matrix Identification strategy for designers. Health Environments Research \& Design Journal, 8(4), $115-130$.

Nejati, A., Shepley, M., Rodiek, S., \& Lee, C. (2016). Restorative design features for hospital staff break areas: A multi-method study. Health Environments Research \& Design Journal, 9(2), $16-35$.

Nightingale, F. (1859). Notes on Nursing. Philadelphia, PA: J.B. Lippincott Company.

Olds, A. R. (1991). With children in mind: Novel approaches to waiting area and playroom design. Journal of Health Care Interior Design, 3, $111-122$.

Park, J. G. (2009). Color perception in pediatric patient room design: Healthy children vs. pediatric patients. Health Environments Research \& Design Journal, 2(3), 6-28.

Park, J. G., \& Park, C. (2013). Color perception in pediatric patient room design: American versus Korean pediatric patients. Health Environments Research \& Design Journal, 6(4), $10-26$.

Rennick, J. E., \& Rashotte, J. (2009). Psychological outcomes in children following pediatric intensive care unit hospitalization: $A$ systematic review of the research. Journal of Child Health Care, 13(2), 128-149.

Roth, M. (2006). Validating the use of Internet survey techniques in visual landscape assessment-An empirical study from Germany. Landscape and Urban Planning, 78(3), 179-192.

Sadler, B. L., \& Joseph, A. (2008). Evidence for innovation: Transforming children's health through the physical environment. Alexandria, VA: National Association of Children's Hospitals and Related Institutions.

Shepley, M. M. (200 1). Research on healthcare environments for children and their families. In A. Dilani (Ed.), Design \& health - The therapeutic benefits of design (pp. 25-29). Stockholm, Sweden: Svensk Byggtjänst.

Shepley, M., Fournier, M., \& McDougal, K. (1998). Healthcare environments for children and their families. Dubuque, 10 : Kendall-Ward.

Stefanatou, A., \& Bowler, D. (1997). Depiction of pain in the self-drawings of children with sickle cell disease. Child: Care, Health and Development, 23, 135-155.

Stowman, S., Kearney, C. A., \& Daphtary, K. (2015). Mediators of initial acute and later posttraumatic stress in youth in a PICU. Pediatric Critical Care Medicine, 16(4), el 13-e 118. 
WEINBERGER ET AL.

Theofanidis, D. (2007). Chronic illness in childhood: Psychosocial adaptation and nursing support for the child and family. Health Science Journal, 2, 1-9.

Tofle, R. B., Schwarz, B., Yoon, S.-Y., Max-Royale, A., \& Des, M. E. (2004). Color in healthcare environments: A research report. Retrieved March 31, 2015 from http://www. deborahburnett. com/images/uploads/Color_in_Healthcare.pdf

Ulrich, R. (1984). View through a window may influence recovery from surgery. Science, 224, 420-421.

Vartanian, O., Navarette, G., Chatteriee, A., Fich, L. B., Gonzalez-Mora, J. L., Leder, H., et al. (2015). Architectural design and the brain: Effects of ceiling height and perceived enclosure on beauty judgments and approach-avoidance decisions. Journal of Environmental Psychology, 41, 10-18.
Vilas, D. (2014, January). Report on findings of play practices and innovations survey: The state of play in North American hospitals. Child Life Council Bulletin, 32(1), 1-43. Retrieved April 9, 2015 from https://www.childlife.org/files/ReportPlayPra cticesInnovationsSurvey.pdf

Weinberger, N., Butler, A., \& Schumacher, P. (2013). Looking inside and out: Perceptions of physical activity in child care spaces. Early Child Development and Care, 184(2), 194-210.

Wells, N. M. (2000). At home with nature effects of "greenness" on children's cognitive functioning. Environment and Behavior, 32(6), 775-795.

Wells, N. M., \& Evans, G. (2003). Nearby nature: A buffer of life stress among rural children. Environment and Behavior, 35(3), $311-330$.

Received February 26, 2016; revised December 5, 2016 ; accepted December 8, 2016

Nanci Weinberger is Professor and Chair of the Department of Applied Psychology at Bryant University in Smithfield, RI. She received her Ph.D. and M.S. degrees in Experimental Psychology with a specialization in Child Development from Tufts University. Dr. Weinberger also has a B.S. degree in Child and the Community from Lesley College and an A.A.S. degree in Nursery Education from State University of New York at Cobleskill. Her research focuses on how childhood environments meet the developmental needs of children. She currently teaches courses in child development, gender development, adult development, and environmental psychology.

Allison G. Butler is an Associate Professor of Applied Psychology at Bryant University in Smithfield, RI. She graduated from The College of William and Mary with a B.S. in Psychology and teaching licensure in Elementary Education. She was a fifth grade teacher before earning her M.Ed. in Educational Psychology from the University of Virginia. Her Ph.D. is in Applied Developmental and Educational Psychology from Boston College. Her research focuses on learning and cognition in K-12 populations, how environments can best support child development, and the use of instructional technology in higher education. She currently teaches courses in educational psychology, child development, psychological testing and assessment, child psychopathology, and introductory psychology.

Beth McGee has a M.S. degree in Interior Architecture from the University of North Carolina Greensboro with a concentration in product design and a B.F.A. from Kendall College of Art and Design emphasizing healthy environments. She has passed the NCIDQ exam and has been licensed to practice in the state of Florida since 2008. She is also a LEED AP and has an interest in integrating biophilia with sustainable and restorative design for optimized healthy environments. She is currently a Ph.D. student at the University of Florida researching biophilia and teaches visual communication, professional practice, and studio design courses. 
WEINBERGER ET AL.

Phyllis A. Schumacher is a Professor of Mathematics at Bryant University in Smithfield, RI. She has taught both graduate and undergraduate students at Bryant for over 40 years. She has served as the Chair of the Department and the Coordinator of the Actuarial Statistics Program. She has also been involved in the K-16 educational arena and has worked on two federal grants where she served as a mentor to middle and high school mathematics teachers in RI. Phyllis earned her Ph.D. in Statistics from the University of Connecticut and also holds an M.S. and B.A. in Mathematics from the University of Rhode Island. Her research interests include gender issues in mathematics education and in technology, and the application of statistics to psychology. She has published articles on these topics in professional journals in psychology, mathematics, and business education.

Ryan Linn Brown completed her B.S. in Applied Psychology at Bryant University with minors in Business Administration, Biology, and Statistics. She has studied abroad at Griffith University in Queensland, Australia while volunteering at Paradise Kids, an organization that offers grief counseling and encourages the natural healing process in children. She was head of public relations for the Bryant Psychology Association. 
This Special Issue could not have been possible without the dedication of the following individuals; many of whom reviewed multiple papers and multiple revisions in order to ensure the highest quality content. The Journal of Interior Design is grateful for your service.

Abimbola Asojo, Ph.D., University of Minnesota Janice Barnes, Ph.D., Perkins + Will

Julie Boettcher, M.S., University of Pittsburgh

Rosalyn Cama, Hon. Doctorate-Fine Arts, CAMA

Nichole Campbell, Ph.D., University of Florida

Candy Carmel-Gilfilen, M.Arch., University of

Florida

Evangelia Chrysikou, Ph.D., University of Kansas

Clare Cooper-Marcus, M.A./M.C.P., University of

California, Berkley

Keith Diaz Moore, Ph.D., University of Utah

Joan Dickinson, Ph.D., Radford University

Joy Dohr, Ph.D., University of Wisconsin-Madison

Paul Eshelman, M.F.A., Cornell University

Mariana Figueiro, Ph.D., Rensselaer Polytechnic

Institute

Nisha Fernando, Ph.D., University of

Wisconsin-Stevens Point

Dorothy Fowles, Ph.D., Iowa State University

Saif Haq, Ph.D., Texas Tech University

Alan Hedge, Ph.D., Cornell University
Ying Hua, Ph.D., Cornell University

Shireen Kanakri, Ph.D., Ball State University

Mihyun Kang, Ph.D., Oklahoma State University

Seunghae Lee, Ph.D., Oregon State University

Lorraine Maxwell, Ph.D., Cornell University

Adeleh Nejati, Ph.D., Texas A\&M University

Jin Gyu Park, Ph.D., University of North Texas

Sharran Parkinson, Ph.D., Texas Tech University

Samira Pasha, Ph.D., CallisonRTKL

Debajyoti Pati, Ph.D., Texas Tech University

Zofia Rybkowski, Ph.D., Texas A\&M University

Hessam Sadatsafavi, Ph.D., Cornell University

Susanne Siepli-Coates, M.Arch., Kansas State

University

Ellen Taylor, Ph.D., Center for Health Design

Judy Theodorson, M.Arch., Washington State

University

Jo Ann Thompson, Ph.D., Washington State

University

Jennifer Webb, Ph.D., University of Arkansas

Nancy Wells, Ph.D., Cornell University

The expanded content of this special double issue on Healthcare Design was made possible, in part, thanks due to the following contributors:

\section{Cornell Institute for Healthy Futures}

Innovating across Health, Hospitality and Design

Cornell Institute for Healthy Futures is the first academic center in the country to combine hospitality, environmental design, and health policy and management into a broad-based platform to improve service in healthcare, wellness, and senior living. http://ihf.cornell.edu/

\section{Robert and Edna Shelley Gates Fund}

Supporting Leadership in Design and Environmental Analysis

Dedicated to advancing the role of design in society, particularly with respect to health issues and underrepresented populations.

\section{Anonymous}

In recognition of the many dedicated educators, scholars and practitioners who work tirelessly to advance design education and practice.

With thanks and admiration for your selfless efforts. 